\title{
Mutations of CX46/CX50 and Cataract Development
}

\author{
Yumeng Shi ${ }^{1}$, Xinbo $\mathrm{Li}^{2 *}$ and Jin Yang ${ }^{1 *}$ \\ ${ }^{1}$ Key Laboratory of Visual Impairment and Restoration of Shanghai, Department of Ophthalmology and Visual Science, Eye Ear \\ Nose and Throat Hospital of Fudan University, Shanghai, China, ${ }^{2}$ Casey Eye Institute, Oregon Health and Science University, \\ Portland, OR, United States
}

Cataract is a common disease in the aging population. Gap junction has been considered a central component in maintaining homeostasis for preventing cataract formation. Gap junction channels consist of connexin proteins with more than 20 members. Three genes including GJA1, GJA3, and GJA8, that encode protein Cx43 (connexin43), Cx46 (connexin46), and Cx50 (connexin50), respectively, have been identified in human and rodent lens. Cx46 together with Cx50 have been detected in lens fiber cells with high expression, whereas Cx43 is mainly expressed in lens epithelial cells. Disrupted expression of the two connexin proteins $\mathrm{C} \times 46$ and $\mathrm{Cx} 50$ is directly related to the development of severe cataract in human and mice. In this review article, we describe the main role of Cx46

OPEN ACCESS

Edited by:

Zhe-Sheng Chen,

St. John's University, United States

Reviewed by:

Pranjal Sarma,

University of Cincinnati, United States

Jie Chen,

Affiliated Eye Hospital of Wenzhou

Medical University, China

*Correspondence: Jin Yang jin_yang@fudan.edu.cn

Xinbo $\mathrm{Li}$

lixinb@ohsu.edu

Specialty section:

This article was submitted to

Molecular Diagnostics and

Therapeutics,

a section of the journal

Frontiers in Molecular Biosciences

Received: 23 December 2021

Accepted: 12 January 2022

Published: 11 February 2022

Citation:

Shi Y, LiX and Yang J (2022) Mutations of CX46/CX50 and

Cataract Development.

Front. Mol. Biosci. 9:842399. doi: 10.3389/fmolb.2022.842399 and $\mathrm{C} \times 50$ connexin proteins in the lens and the relationship between mutations of Cx46 or Cx50 and hereditary cataracts. Furthermore, the latest progress in the fundamental research of lens connexin and the mechanism of cataract formation caused by lens connexin dysfunction are summarized. Overall, targeting connexin could be a novel approach for the treatment of cataract.

Keywords: gap junction, Cx46, Cx50, cataract, lens microcirculation, oxidative stress

\section{INTRODUCTION}

Cataract is the opacity of lens and the most important cause of low vision and blindness worldwide. Cataract can be divided into metabolic cataract, age-related cataract, congenital cataract and others. With the increase of the elderly population, there are more and more agedrelated cataract. Congenital cataract is the main cause of blindness in children, exerting a dramatic impact on their quality of life. Therefore, the prevention and treatment of cataract is particularly important. Lens homeostasis is critical to its transparency, and its imbalance can lead to cataract.

The lens is a biconvex transparent tissue situated between the iris and the vitreous, composed of a single layer of epithelial cells under the anterior capsule and the enormous lens fibers differentiated from epithelial cells (Ruan et al., 2020). Epithelial cells at the lens equator region migrate laterally toward the equator, where they transform into differentiating fiber cells and finally turn into mature fiber cells through extensive cell elongation. The lens is able to transmit light via the contraction or relaxation of the ciliary muscle and focus light onto the retina (Summers et al., 2021). In order to increase light transmission and minimize light scattering, various organelles including the Golgi apparatus, endoplasmic reticulum, and nucleus are degraded in the differentiating lens fibroblasts (Brennan et al., 2018; Brennan et al., 2021). In addition, lens crystallins are at high concentration in the lens to enable appropriate refractive ability that aids in light transmission and focusing (Cvekl and Eliscovich, 2021). 


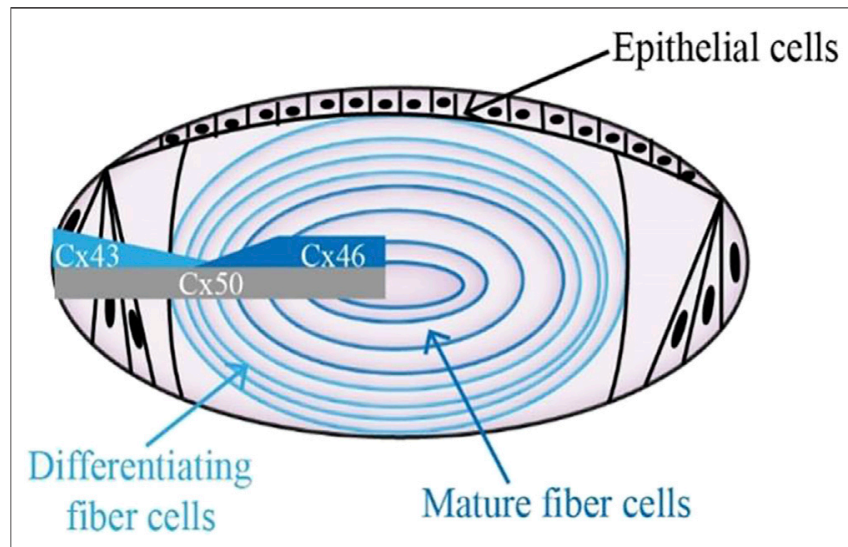

FIGURE 1 | Diagram showing the distribution of connexin hemichannels in the lens. Connexin isoform $\mathrm{Cx} 43$ is mainly expressed in the anterior epithelial layer. $\mathrm{Cx} 46$ can be found in the differentiating lens fibroblasts and mature lens fibroblasts. The expression of Cx50 stays the course of entire lens development.

Gap junction channels are critical in regulating the lens microcirculation system, which is crucial for the motion of the ions and other medium to maintain lens homeostasis (Brink et al., 2020; Valiunas et al., 2019; Valiunas and White, 2020). Moreover, gap junctional communication is a way to maintain normal lens fiber cells physiology and tissue functions (Van Campenhout et al., 2021). Gap junction channels facilitate these processes by permitting the selective passage of ions and other molecules, forming both electrical and biochemical coupling between cells. Gap junction channels are assembled by the coaxial alignment of two hemichannels. Six connexin molecules oligomerize into a hemichannel (also called connexon) (Beyer and Berthoud, 2014). Connexins are a family of structurally related transmembrane proteins in humans with approximately 20 members. Every single connexin protein consists of four transmembrane domains (T1-T4), two extracellular loops (EL1, EL2) with a cytoplasmic loop (IL), and cytoplasmic $\mathrm{N}$-terminal and C-terminal components (Figueroa et al., 2019; Mese et al., 2007; Sánchez et al., 2019). Three connexins presented in the lens are a $1(\mathrm{Cx} 43), a 3(\mathrm{Cx} 46)$, and $\alpha 8$ (Cx50), which are encoded by three genes: Gja1, Gja3, and Gja8, respectively (Yue et al., 2021; Ping et al., 2021). In the layer of lens epithelial cells, abundant expression of $\mathrm{Cx} 43$ could be detected, whereas $\mathrm{Cx} 46$ is exclusively present in the lens fiber cell, where its expression corresponds with fiber cell differentiation, and Cx50 is widely expressed in both lens epithelial and fiber cells (Figure 1) (Paul et al., 1991; Delvaeye et al., 2018; Ceroni et al., 2019; Tong et al., 2021). Although the pathogenesis of cataracts is not yet fully clear (Davison, 2020; Hashemi et al., 2020; Shiels and Hejtmancik, 2021; Taylan Sekeroglu and Utine, 2021), a number of studies have shown that disruption of lens connexin hemichannels proteins $\mathrm{Cx} 46$ and $\mathrm{Cx} 50$ expression are associated with cataract formation (White et al., 1998; Chang et al., 2002; Addison et al., 2006; Xia et al., 2006a).

\section{CX46 AND CX50 IN CATARACT FORMATION}

\section{Mutations of Cx46 and Cx50 Identified in Human and Rodents With Cataracts}

More than 40 different mutations associated with cataractogenesis have been identified in the gene region of GJA3 and GJA8 in human pedigrees (Table 1). The first variant P-to-S transition at site 88 in $\mathrm{Cx} 50$ was identified in a British family with zonular pulverulent or "dust-like" cataracts (Mese et al., 2007). Subsequently, two mutations in the GJA3 gene have also been reported in different families with inherited congenital cataracts (Mackay et al., 1999).

More variants of these two connexin hemichannels have been reported in families in recent years. A heterozygous G-to-A substitution in the exon region of GJA3 gene was detected and resulted in the replacement of Asp with Gly at the N-terminus of Cx46 protein in a Chinese family with congenital nuclear pulverulent and posterior polar cataract (Rees et al., 2000). Another $\mathrm{Cx} 46$ variant, $\mathrm{R} 76 \mathrm{H}$, was identified in a large Australian cataract pedigree with zonular pulverulent cataract by using linkage analysis (Ping et al., 2021). Most of these mutations in the $\mathrm{Cx} 46$ protein are present in the N-terminal, the first transmembrane, and extracellular domains. One missense mutation N188T and another frameshift mutation at the position S380Qfs of Cx46 gene were found to be related to hereditary autosomal dominant cataract in two different Chinese families (Paul et al., 1991; Li et al., 2004). In addition, a missense mutation in the $\mathrm{Cx} 46$ coding region occurred in a Chinese cataract pedigree, giving rise to the dysfunction of the $\mathrm{Cx} 46$ protein, which might be potentially linked to the development of congenital nuclear cataract. Methionine substituted for valine at site 44 (V44M) in the Cx46 gene is responsible for that mutation (Chen et al., 2017).

Similar to $\mathrm{Cx} 46$, numerous mutations of the $\mathrm{Cx} 50$ gene have been identified. The first Cx50 mutation from a British family with zonular pulverulent cataract was identified at the second transmembrane domain of the encoded gene (Mese et al., 2007). Subsequently, Glu48Lys was the second recognized mutation reported in a three-generation Pakistani family (Berry et al., 1999). A missense variation V64G of Cx50 conserved residues in a Chinese family occurred at the phylogenetically conserved extracellular loop1 (Sharan et al., 2005). The autosomal dominant lamellar pulverulent cataract from a four-generation British family is associated with two mutations located at P88S and P88Q of GJA8, resulting from a 262C > A transition (Arora et al., 2006). In addition, an insertion mutation at codon 203 of GJA8 was mapped in a southern Indian family with autosomal recessive cataract, producing a functionally null allele and the subsequent reduction of transmembrane domain, cytoplasmic domain, and the second extracellular domain, and was different from the vast majority of mutations recognized with dominant features (Ponnam et al., 2007). Recently, a new variation at site 166 (c.166A > C) in Cx50 coding region was confirmed by the comprehensive screening by next-generation sequencing in a Mauritanian family with 
TABLE 1 | Summary of Cx46 and Cx50 mutants associated with cataract formation.

\begin{tabular}{|c|c|c|c|}
\hline Mutation & Cataract type & Family origin & References \\
\hline N63S & zonular pulverulent & British & Mackay et al. (1999) \\
\hline $\mathrm{R} 76 \mathrm{H}$ & zonular pulverulent & Australian & Ping et al. (2021) \\
\hline N188T & nuclear pulverulent & Chinese & Li et al. (2004) \\
\hline V44M & nuclear & Chinese & Chen et al. (2017) \\
\hline \multicolumn{4}{|l|}{ Human Cx50 } \\
\hline E48K & zonular nuclear pulverulent & Pakistani & Berry et al. (1999) \\
\hline V64G & nuclear & Chinese & Sharan et al. (2005) \\
\hline P88S, P88Q & lamellar pulverulent & British & Arora et al. (2006) \\
\hline T56P & nuclear & Mauritanian & Hadrami et al. (2019) \\
\hline S217P & perinuclear & Chinese & Li et al. (2019) \\
\hline \multicolumn{4}{|l|}{ Rat $\mathrm{C} \times 46$} \\
\hline E42K & nuclear & Cataract rat strain & Yoshida et al. (2005) \\
\hline S50P & whole cataract and small eye & ENU mutagenesis & Xia et al. (2006b) \\
\hline \multicolumn{4}{|l|}{ Rat $C \times 50$} \\
\hline R340W & cataract & UPL rat strain & Yamashita et al. (2002) \\
\hline
\end{tabular}

congenital nuclear cataracts (Hadrami et al., 2019). Moreover, a novel missense mutation of c.217T $>\mathrm{C}$ in a four-generation Chinese family with autosomal dominant congenital cataract (ADCC) was identified, resulting from a serine-to-proline interchange at residue 73 of the Cx50 gene (Li et al., 2019).

In addition to humans, mutations of $\mathrm{Cx} 46$ and $\mathrm{Cx} 50$ in homozygous mice can cause cataracts. Targeted deletion of GJA3 and GJA8 genes in mice can develop into a dominant or semi-dominant cataract pattern. Abundant mutations have been reported in mice. A single A-to- $\mathrm{C}$ transversion within codon 47 was amplified and sequenced in the $\mathrm{Cx} 50$ protein-coding regions in No2 cataractous mouse, resulting in congenital hereditary cataracts (Steele et al., 1998). Furthermore, an ethylnitrosourea mutagenesis screen analysis revealed a new cataract mutation, Val-to-Ala interchange at codon 64 of Cx50, in mice with phenotypically hereditary congenital cataracts (Graw et al., 2001). Lens opacity 10 (Lop10) mutation at chromosome 3 and a missense single transversion (G-to-C) in the Cx50 coding region was identified in a mouse that developed microphthalmia with dense cataracts, resulting in Glyto-Arg substitution at codon 22 (Chang et al., 2002). Moreover, another variant S50P in the Cx50 protein was reported to be associated with smaller lens (Xia et al., 2006b). Apart from mice, connexin mutations have also been detected in rats with cataracts. A C-to-T transversion located at codon 340 in the Cx50 genes was strongly associated with the development of cataracts in the Upjohn Pharmaceuticals Limited (UPL) rat model (Yamashita et al., 2002). A missense mutation at site E42K in the coding region of $\mathrm{Cx} 46$ from rats with congenital nuclear cataracts was reported (Yoshida et al., 2005). Only a few mutations in rodents have been utilized for the investigation of gap junction channel, and therefore it is necessary for us to broaden the related studies.

\section{The Relationship Between Connexin Hemichannels and Cataract Formation}

Mathia et al. pointed out that the lens develops an internal circulation system that deliver water, ions, and solute for lens cells to replenish its lack of blood supply (Mathias et al., 2007). It allows nutrients and ions to enter the lens from both the anterior and posterior and to migrate to the center across the extracellular spaces, and unwanted metabolites to exit at the lens equator. The lens is full of plentiful and functional ion channels and transporters that support the internal circulation system. Dysfunction of the lens circulation system has been postulated to linked to cataract formation (Berthoud et al., 2020). Lens gap junctions formed by two oligomeric subunits referred to as hemichannels (also called connexons) display a critical effect on the lens internal circulation system. Both Cx46 and Cx50 form functional homomeric/homotypic gap junction channels and hemichannels. In vitro studies demonstrate that majority of lens connexin mutations linked to congenital cataracts will decrease coupling conductance and influence lens circulation (Gong et al., 2007; Berthoud and Ngezahayo, 2017). Most mutations of the $\mathrm{Cx} 46$ and $\mathrm{Cx} 50$ gene leading to cataracts are recognized as autosomal dominant, but several mutations that have been investigated are non-functional in terms of expression systems (Gerido et al., 2003). Apart from that, connexin variants with increased hemichannel activity could affect lens circulation through cell depolarization, which would reduce the ability of ions and other signals to migrate throughout the organ.

As previously reported, Cx50 knockout mice developed smaller eyes and lens-32 and $46 \%$ size reduction in the mass of control littermates, respectively (Gerido et al., 2003). Several studies observed that targeted deletion of GJA8 in mice led to delay in cell denucleation, indicating an important part of $\mathrm{Cx} 50$ in 
lens fibroblast maturation and epithelial cell proliferation (Graw et al., 2001; Sellitto et al., 2004). The expression of Cx50 in place of Cx46 by gene knock-in did not rescue epithelial proliferation, implying that $\mathrm{Cx} 50$, but not $\mathrm{Cx} 46$, facilitates normal lens growth and development after growth factor stimulation (Yamashita et al., 2002; White et al., 2007; Minogue et al., 2017).

Substantial studies have revealed that knockout of $\mathrm{Cx} 46$ gene in mice leads to the impairment of lens transparency and the development of nuclear cataracts, probably caused by accumulation of crystallin cleavage products and production of an insoluble complex of disulfide-associated polypeptides (Gong et al., 1997). In addition, the coupling conductance was completely eliminated when the lens fiber matured, while the conductance in differentiated fibers was greatly reduced. Cx46 deletion-induced nuclear cataracts are also strongly correlated with the elevation of intracellular $\mathrm{Ca}^{2+}$ and corresponding change of increased protein degradation in lens fiber cells (Baruch et al., 2001). Change in gap junction communication due to mutations in the lens may be one of the important reasons for the formation of cataracts (Sharan et al., 2005; Schadzek et al., 2019).

Recent studies demonstrated that mutations in connexin hemichannels have a great impact on the function of gap junction channels. A missense mutation with an Asp-to-Ala substitution at site 47 in the first extracellular domain of $\mathrm{Cx} 50$ protein in No2 mice resulted in the loss of ability to produce functional gap junction channels, leading to cataractogenesis (Katai et al., 1999). A G-to-A transition mutation at position 139 was identified in the coding region of Cx50 from a family with autosomal dominant nuclear pulverulent cataracts, and also resulted in the loss of ability to generate functional gap junction channels in paired oocytes (Schadzek et al., 2019). Mixed hemichannels consisting of normal and abnormal Cx50 or $\mathrm{Cx} 46$ proteins in the lens displayed remarkably altered gating properties and coupling conductance, which may give rise to cataract formation. It is still unknown what the specific role of connexin hemichannels in the lens is.

\section{POSSIBLE MECHANISMS OF CATARACTS RELATED TO LENS CONNEXIN \\ Lens Microcirculation and Biomineralization}

It is generally known that gap junction channels could maintain the homeostasis of ocular lens by propagating lens microcirculation. Under normal conditions, the circuit of the lens microcirculation is completed when $\mathrm{Na}^{+} / \mathrm{K}^{+}$-ATPase or $\mathrm{Na}^{+} /$ $\mathrm{Ca}^{2+}$ exchanger and $\mathrm{Ca}^{2+}$-ATPase on epithelial cells transport $\mathrm{Na}^{+}$and $\mathrm{Ca}^{2+}$ ions out of the lens when these intracellular ions are located at the surface of cell (Delamere and Tamiya, 2004; De Maria et al., 2018). Such pumps can produce low intracellular sodium and calcium concentration and form an electrochemical environment (Alvarez et al., 2001; Alvarez et al., 2003; Okafor et al., 2003). To maintain the $\mathrm{Na}^{+} / \mathrm{Ca}^{2+}$ gradient, gap junction channels of the lens regulate circulation system through passive diffusion. Disruption of the lens microcirculation has been implicated in cataract pathogenesis. In the normal mouse lens, differentiating fiber gap junctions facilitate sodium ion flow to the equator once it enters the intercellular compartment. However, it has been found that the intercellular concentration of $\mathrm{Na}^{+}$ becomes promoted in lenses isolated from mice expressing Cx46-and Cx50-dominant mutants (Gao et al., 2018). Moreover, loss of $\mathrm{Cx} 46$ causes calcium accumulation and subsequent elevation in the activity of Lp82, which is a type of $\mathrm{Ca}^{2+}$-dependent protease that generate $\gamma$-crystallin cleavage products (Baruch et al., 2001; Ebihara et al., 2003). Measurement of calcium in Cx46 knockout has demonstrated that loss of intracellular coupling leads to the blockage of the efflux path to accumulate $\mathrm{Ca}^{2+}$ (Gao et al., 2004). There is also a hypothesis that reduction of $\mathrm{Cx} 46$ and $\mathrm{Cx} 50$ levels alter the function of gap junction channels in regulating the circulation of lens internal mediums, bringing about further changes to other major components in the lens microcirculation. These experimental evidences offer additional support that calcium displays different distribution patterns in wild-type, knockout and knock-in lens in microcirculation models.

Calcium has also been reported to be tightly related to the development of cataracts (Gerido et al., 2003). Different etiologies of cataract lenses in humans and mice contained increased $\mathrm{Ca}^{2+}$ (Vanden Abeele et al., 2006). Elevation of intracellular calcium concentration and corresponding elevated protein degradation in lens fibroblasts due to loss of $\mathrm{Cx} 46$ gene are associated with nuclear cataract formation (Liu et al., 2015). Calpain II, a kind of $\mathrm{Ca}^{2+}$-dependent protease, induces the development of nuclear cataracts in $\mathrm{Cx} 46$ knockout lenses by cleaving crystallin proteins (Baruch et al., 2001). Proteolysis caused by calpain has also been shown to play a role in the truncation of Cx50 (Xia et al., 2006a). Gap junction coupling is also impaired due to sharply declined levels of $\mathrm{Cx} 46$ and $\mathrm{Cx} 50$ proteins and elevated total calcium concentration in cataract lens from homozygous $\beta$-crystallin S11R-mutant mice (Li et al., 2010). Abundant investigations demonstrate an important role of calmodulin (CaM) in maintaining functional gap junction channels. Increased $\mathrm{Cx}$ hemichannel activity is mediated by increased intercellular $\mathrm{Ca}^{2+}$ concentration and the activation of CaM. The voltage from oocytes expressing Cx46 G143R loses control of hemichannels, which forms a leaky gate, leading to diminish voltage-dependent ionic conductance ( $\mathrm{Li}$ et al., 2008). A sequence of results showed that loss of cell-cell communication impairs the movement of ions such as $\mathrm{Na}^{+}$and $\mathrm{Ca}^{+}$towards the epithelium, inducing an alteration of $\left[\mathrm{Na}^{+}\right]_{\mathrm{i}}$ and $\left[\mathrm{Ca}^{+}\right]_{\mathrm{i}}$ gradient in $\mathrm{Cx} 46 \mathrm{fs} 380$ mice lenses (Berthoud et al., 2014). These alterations lead to a vicious spiral that could ultimately exacerbate the occurrence of cataracts. Thus, extrapolation to humans shows that people suffering from severely declined levels of connexin or damaged gap junction function may develop cataracts on account of lens microcirculation disorders.

Numerous observations suggest that accumulation of insoluble calcium salts results in the development of cataracts. It probably likely that $\mathrm{Ca}^{+}$would precipitate due to the high concentration of more than $1 \mu \mathrm{M}$ in the center of the lens, forming insoluble calcium salts (Berthoud et al., 2019). Moreover, using Alizarin acid staining identified immobile and 
insoluble $\mathrm{Ca}^{+}$in cataractous lenses from Cx46 and Cx50 knockout mice (Gao et al., 2018). These finding may be consistent with calcium oxalate or calcium carbonate crystals found in cataracts patients.

Biomineralization occurs when insoluble precipitates comprising inorganic ions deposit and form mixed particles. Impaired lens circulation in $\mathrm{Cx} 46$ and $\mathrm{Cx} 50$ knockout mice caused cataracts though $\mathrm{Ca}^{+}$accumulation, precipitation, and biomineralization (Gao et al., 2013). Moreover, modification of the connexins, including via proteolysis, ubiquitination, and phosphorylation, may alter lens microcirculation and affect subsequent biomineralization in the lens (Retamal et al., 2019). The mixed deposits in cataractous lenses might comprise of aggregated non-functional proteins and precipitated $\mathrm{Ca}^{+}$. Detection of the $\mathrm{Ca}^{+}$values in cataractous human lenses revealed that the insoluble lens fraction contained a higher proportion of $\mathrm{Ca}^{+}$than the soluble part. Lens biomineralization is probably the main reason for the development of cataracts of additional pathogenesis.

\section{Age-dependent Truncations}

It is universally acknowledged that age-related connexin modification could deteriorate the intercellular communications between lens cells. Over $90 \%$ of downregulated expression of $\mathrm{Cx} 46$ and $\mathrm{Cx} 50$ proteins has been detected in normal lens fiber cells isolated from a group of cataracts patients aged more than 50 years old (Gong et al., 2021). The expression of Cx46 and Cx50 proteins displayed age-dependent reduction, whereas $\mathrm{Cx} 43$ remained relatively stable in aging mice. Two mutations in the Cx46 and Cx50 code region, Cx46V139M and Cx50V275I, respectively, were identified with mild association with the development of agerelated cataracts in a Chinese population (Zhou et al., 2011). These mutants show the impact on alterations in posttranslational modifications (PTMs) of connexin proteins because of age of appearance of cataracts. Polymorphisms in the intronic region of the $\mathrm{Cx} 50$ gene and a C-to-G substitution in the code region of $\mathrm{Cx} 46$ gene might be linked to the formation of age-related cataracts (Liu et al., 2011; Zhou et al., 2011). Previous studies indicate that an age-dependent decrease of gap junction conductance induces alterations in the ability of ion channels and related transporters in the lens. There is a hypothesis that elimination of over $65 \%$ of connexin proteins caused by agerelated modifications is responsible for the declined coupling levels in the lens.

With increasing age, truncations in the cytoplasmic loop region and $\mathrm{N}$-terminal domain of $\mathrm{Cx} 46$ and $\mathrm{Cx} 50$ accumulate in the core, resulting in decreased coupling conductance (White et al., 2007). In addition, the corresponding abundance of these truncations was remarkably altered with aging of lens fiber cells, showing the highest level of truncation products in the nucleus of the oldest fiber cells and the lowest level in the outer cortex of younger, differentiating fiber cells. Previous studies in rodent lens indicated that the levels of agerelated connexin hemichannel truncations in younger lenses were lower than those found in older lenses. It is likely that the PTMs of these connexins are dependent on the age of the lens
(Rozema and Ní Dhubhghaill, 2020; Fan and Monnier, 2021). The epithelial cells of lens differentiate into fiber cells and the C-terminal of $\mathrm{Cx} 46$ and $\mathrm{Cx} 50$ proteins are cleaved during this process. The endogenous $\mathrm{Cx} 50$ truncations resulted from the enzymolysis of calpain or other proteases. Mass spectrometry analysis identified several truncation sites of $\mathrm{Cx} 46$ and $\mathrm{Cx} 50$ proteins in bovine lens. C-terminal truncation at site V284 of Cx50 induced nonfunctional hemichannels; in contrast, truncation at position TM4 had no influence on its properties (Slavi et al., 2016). Therefore, cleavage of Cx50 by calpain is able to decrease the proportion of functional connexin hemichannels, and give rise to reduced level of gap junction coupling during lens development. The calpain activity decreases with age in the Cx46 knockout lenses. C-terminal cleavage of $\mathrm{Cx} 46$ has no impact on coupling conductance, and ionic permeability of connexin hemichannels composed of truncated $\mathrm{Cx} 46$ possessed almost the same function as the full-length isoform (Fan and Monnier, 2021). However, the mechanism attributed to truncations in $\mathrm{Cx} 46$ and $\mathrm{Cx} 50$ with differentiation and aging remains to be determined.

\section{Other factors: Oxidative Stress and Hypoxia}

Oxidative stress is responsible for the production of highly reactive oxygen species (ROS) and subsequent cellular damage at protein and DNA level has been observed in cataractous lens (Babizhayev and Bozzocosta, 1994; Lin and Takemoto, 2005). To combat constant oxidative stress from the environment, ocular tissue normally produces high concentrations of reduced glutathione (GSH) and utilizes a complicated antioxidant defense system composed of superoxide dismutase (SOD) and glutathione peroxidase (GPX). It is widely recognized that GSH plays an important role in maintaining redox homeostasis and lens transparency (Ho et al., 1997; Delamere and Tamiya, 2004). Depletion of GSH in newborn mice compromise lens transparency and eventually leads to the development of cataract (Laver et al., 1993). Plentiful evidence has been gathered to inform that cataract formation can result from oxidative stress, decreased level of GSH, and the mixed protein-thiol and protein-protein disulfide bonds. Increased levels of GSH and oxidized glutathione (GSSG) have been measured in the core of lens as it ages (Lim et al., 2020). Misfold proteins caused by mutations in some of the connexins presumably deposit in the Golgi bodies or endoplasmic reticulum (ER) to trigger stress responses and ultimately damage crystalline proteins. The Cx46fs380mutant mice exhibited reduced total levels of $\beta$-crystallins consistent with degradation, modification, and truncation of the proteins (Minogue et al., 2005). A decreased GSH level was only observed in the nucleus of homozygous Cx46fs380 lens (Jara et al., 2020). However, a single mutation of P-to-S transversion at amino acid residue 88 of human $\mathrm{Cx} 50$ protein resulted in cytosolic aggregates and led to decreased degradation. In addition, a higher level of GSH was observed in homozygous Cx50D47A lens about 2 months old (Jara et al., 2020). Detection of the level of GSH in the lens 


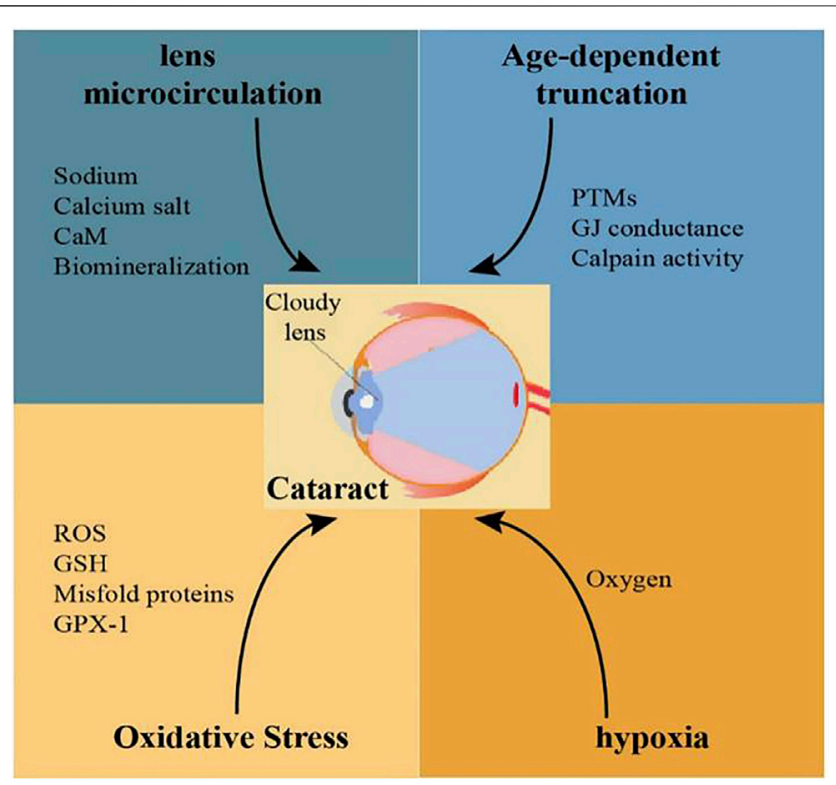

FIGURE 2 | Possible mechanisms related to Cx46 and Cx50 mutations involved in the pathogenesis of cataracts.

from connexin-knockout mice suggested that $\mathrm{Cx} 46$ (not Cx50) is essential for the movement of GSH from lens cortical cell to lens nuclear cell, under the condition that both $\mathrm{Cx} 46$ and $\mathrm{Cx} 50$ hemichannels assist in the transport of GSH (Serebryany et al., 2021). Mutation in the Cx46 gene region in mice led to the development of lens opacity and cataracts due to deposit of insoluble polypeptides caused by aggregation of crystallin cleavage products (Gong et al., 1997; King and Lampe, 2005; Kelly et al., 2007).

It has been suggested that targeted deletion of GPX-1 in mice can cause declined expression level of Cx46 and Cx50 together with extremely low level of coupling conductance (Wang et al., 2009). Apart from that, hydrogen peroxide was reported to keep Cx50 hemichannels open, and can assist in the movement of reductant glutathione into lens fiber cells. Both Cx50P88S and $\mathrm{Cx} 50 \mathrm{H} 156 \mathrm{~N}$ mutations suppress permeability activity of Cx50 hemichannels (Shi et al., 2018). In addition, oxidative stress cause by 4-hydroxynonenal (4-HNE) can deprive the natural properties of Cx46 protein through its carbonylation (Retamal et al., 2020). These mutants ultimately induce apoptosis of lens epithelial cells and fiber cells.

\section{REFERENCES}

Addison, P. K., Berry, V., Holden, K. R., Espinal, D., Rivera, B., Su, H., et al. (2006). A Novel Mutation in the Connexin 46 Gene (GJA3) Causes Autosomal Dominant Zonular Pulverulent Cataract in a Hispanic Family. Mol. Vis. 12, 791-795. doi:10. 1016/j.visres.2006.01.022

Alvarez, L. J., Candia, O. A., and Polikoff, L. A. (2003). Beta-Adrenergic Stimulation of Na+-K+-2Cl- Cotransport Activity in the Rabbit Lens. Exp. Eye Res. 76 (1), 61-70. doi:10.1016/s0014-4835(02)00254-3
A hypoxic condition is necessary for normal growth and development of the lens. Increased exposure to oxygen has been proven to be a threatening cause for the occurrence of age-related cataracts and nuclear cataracts (Brennan et al., 2020). In vivo studies showed that physiological hypoxia is indispensable for inhibiting cell proliferation and preserving smaller lens size (Zhao et al., 2020). Hypoxia might be a critical factor that regulate the expression and function of $\mathrm{Cx} 46$ in natural lens. The $\mathrm{Cx} 46$ promoter showed tight transcriptional responses when cultured with $1 \%$ oxygen in human lens cells (Molina and Takemoto, 2012). Further studies will be needed to elucidate the change of oxygen concentration in responding to the expression of connexin proteins in the lens.

\section{CONCLUSION AND FUTURE DIRECTIONS}

Remarkable progress and achievement have been obtained in the last few decades in our basic knowledge of the role of lens connexin hemichannels $\mathrm{Cx} 46$ and $\mathrm{Cx} 50$ in cataract formation. Connexin variants related to congenital cataracts are being identified in many regions around the world. Adequate and useful animal models have been generated for the investigation of the role of mutant connexin in lens abnormalities during cataractogenesis. The factors that mutate lens connexin in human and rodents and the mechanisms of cataract formation caused by lens connexin mutation and dysfunction could be explored in the future (Figure 2). Despite all the great achievements, much remains to be seen how $\mathrm{Cx} 46$ and $\mathrm{Cx} 50$ proteins are regulated in the lens under both normal and abnormal conditions. Furthermore, the clinical diagnosis, treatment and prevention based on connexin biology in cataracts are limited. Future investigations should also be arranged to develop effective therapeutic interventions against cataracts.

Mutations of Cx46 and Cx50 in human and rodents can be caused by age, oxidative stress, and hypoxia. Reduced levels of $\mathrm{Cx} 46$ and $\mathrm{Cx} 50$ proteins or these nonfunctional connexin proteins in lens fiber cells would cause disrupted lens microcirculation, and ultimately, development of cataracts.

\section{AUTHOR CONTRIBUTIONS}

JY created the whole manuscript. YS wrote the paper and XL revised the paper.

Alvarez, L. J., Candia, O. A., Turner, H. C., and Polikoff, L. A. (2001). Localization of a $\mathrm{Na}+-\mathrm{K}+-2 \mathrm{Cl}-$ Cotransporter in the Rabbit Lens. Exp. Eye Res. 73 (5), 669-680. doi:10.1006/exer.2001.1075

Arora, A., Minogue, P. J., Liu, X., Reddy, M. A., Ainsworth, J. R., Bhattacharya, S. S., et al. (2006). A Novel GJA8 Mutation Is Associated with Autosomal Dominant Lamellar Pulverulent Cataract: Further Evidence for gap Junction Dysfunction in Human Cataract. J. Med. Genet. 43 (1), e2. doi:10.1136/jmg.2005.034108

Babizhayev, M., and Bozzocosta, E. (1994). Lipid Peroxide and Reactive Oxygen Species Generating Systems of the Crystalline Lens. Biochim. 
Biophys. Acta (Bba) - Mol. Basis Dis. 1225 (3), 326-337. doi:10.1016/09254439(94) $90014-0$

Baruch, A., Greenbaum, D., Levy, E. T., Nielsen, P. A., Gilula, N. B., Kumar, N. M., et al. (2001). Defining a Link between gap junction Communication, Proteolysis, and Cataract Formation. J. Biol. Chem. 276 (31), 28999-29006. doi:10.1074/jbc.m103628200

Berry, V., Mackay, D., Khaliq, S., Francis, P. J., Hameed, A., Anwar, K., et al. (1999). Connexin 50 Mutation in a Family With Congenital "zonular Nuclear" Pulverulent Cataract of Pakistani Origin. Hum. Genet. 105 (1-2), 168-170. doi:10.1007/s004399900094

Berthoud, V. M., and Ngezahayo, A. (2017). Focus on Lens Connexins. BMC Cell Biol. 18 (Suppl. 1), 6. doi:10.1186/s12860-016-0116-6

Berthoud, V. M., Gao, J., Minogue, P. J., Jara, O., Mathias, R. T., and Beyer, E. C. (2020). Connexin Mutants Compromise the Lens Circulation and Cause Cataracts through Biomineralization. Int. J. Mol Sci. 21 (16), 5822. doi:10. 3390/ijms21165822

Berthoud, V. M., Gao, J., Minogue, P. J., Jara, O., Mathias, R. T., and Beyer, E. C. (2019). The Connexin50D47A Mutant Causes Cataracts by Calcium Precipitation. Invest. Ophthalmol. Vis. Sci. 60 (6), 2336-2346. doi:10.1167/iovs.18-26459

Berthoud, V. M., Minogue, P. J., Yu, H., Snabb, J. I., and Beyer, E. C. (2014). Connexin46fs 380 Causes Progressive Cataracts. Invest. Ophthalmol. Vis. Sci. 55 (10), 6639-6648. doi:10.1167/iovs.14-15012

Beyer, E. C., and Berthoud, V. M. (2014). Connexin Hemichannels in the Lens. Front. Physiol. 5, 20. doi:10.3389/fphys.2014.00020

Brennan, L. A., McGreal-Estrada, R., Logan, C. M., Cvekl, A., Menko, A. S., and Kantorow, M. (2018). BNIP3L/NIX Is Required for Elimination of Mitochondria, Endoplasmic Reticulum and Golgi Apparatus during Eye Lens Organelle-free Zone Formation. Exp. Eye Res. 174, 173-184. doi:10. 1016/j.exer.2018.06.003

Brennan, L., Disatham, J., and Kantorow, M. (2020). Hypoxia Regulates the Degradation of Non-Nuclear Organelles during Lens Differentiation through Activation of HIF1a. Exp. Eye Res. 198, 108129. doi:10.1016/j. exer.2020.108129

Brennan, L., Disatham, J., and Kantorow, M. (2021). Mechanisms of Organelle Elimination for Lens Development and Differentiation. Exp. Eye Res. 209, 108682. doi:10.1016/j.exer.2021.108682

Brink, P. R., Valiunas, V., and White, T. W. (2020). Lens Connexin Channels Show Differential Permeability to Signaling Molecules. Int. J. Mol Sci. 21 (18), 6943. doi:10.3390/ijms 21186943

Ceroni, F., Aguilera-Garcia, D., Chassaing, N., Bax, D. A., Blanco-Kelly, F., Ramos, P., et al. (2019). New GJA8 Variants and Phenotypes Highlight its Critical Role in a Broad Spectrum of Eye Anomalies. Hum. Genet. 138 (8-9), 1027-1042. doi:10.1007/s00439-018-1875-2

Chang, B., Wang, X., Hawes, N. L., Ojakian, R., Davisson, M. T., Lo, W., et al. (2002). A Gja8 (Cx50) point Mutation Causes an Alteration of Alpha3 Connexin (Cx46) in Semi-dominant Cataracts of Lop10 Mice. Hum. Mol. Genet. 11 (5), 507-513. doi:10.1093/hmg/11.5.507

Chen, L., Su, D., Li, S., Guan, L., Shi, C., Li, D., et al. (2017). The Connexin 46 Mutant (V44M) Impairs gap junction Function Causing Congenital Cataract. J. Genet. 96 (6), 969-976. doi:10.1007/s12041-017-0861-0

Cvekl, A., and Eliscovich, C. (2021). Crystallin Gene Expression: Insights from Studies of Transcriptional Bursting. Exp. Eye Res. 207, 108564. doi:10.1016/j. exer.2021.108564

Davison, J. E. (2020). Eye Involvement in Inherited Metabolic Disorders. Ther. Adv. Ophthalmol. 12, 2515841420979109. doi:10.1177/2515841420979109

De Maria, A., Zhao, H., and Bassnett, S. (2018). Expression of Potassiumdependent Sodium-Calcium Exchanger in the Murine Lens. Exp. Eye Res. 167, 18-24. doi:10.1016/j.exer.2017.11.002

Delamere, N. A., and Tamiya, S. (2004). Expression, Regulation and Function of $\mathrm{Na}, \mathrm{K}-\mathrm{ATP}$ ase in the Lens. Prog. Retin. Eye Res. 23 (6), 593-615. doi:10.1016/j. preteyeres.2004.06.003

Delvaeye, T., Vandenabeele, P., Bultynck, G., Leybaert, L., and Krysko, D. V. (2018). Therapeutic Targeting of Connexin Channels: New Views and Challenges. Trends Mol. Med. 24 (12), 1036-1053. doi:10.1016/j.molmed. 2018.10.005

Ebihara, L., Pal, J. D., and Pal, J. D. (2003). Effect of External Magnesium and Calcium on Human Connexin46 Hemichannels. Biophysical J. 84 (1), 277-286. doi:10.1016/s0006-3495(03)74848-6
Fan, X., and Monnier, V. M. (2021). Protein Posttranslational Modification (PTM) by Glycation: Role in Lens Aging and Age-Related Cataractogenesis. Exp. Eye Res. 210, 108705. doi:10.1016/j.exer.2021.108705

Figueroa, V. A., Jara, O., Oliva, C. A., Ezquer, M., Ezquer, F., Retamal, M. A., et al. (2019). Contribution of Connexin Hemichannels to the Decreases in Cell Viability Induced by Linoleic Acid in the Human Lens Epithelial Cells (HLE-B3). Front. Physiol. 10, 1574. doi:10.3389/fphys.2019.01574

Gao, J., Minogue, P. J., Beyer, E. C., Mathias, R. T., and Berthoud, V. M. (2018). Disruption of the Lens Circulation Causes Calcium Accumulation and Precipitates in Connexin Mutant Mice. Am. J. Physiology-Cell Physiol. 314 (4), C492-C503. doi:10.1152/ajpcell.00277.2017

Gao, J., Sun, X., Martinez-Wittinghan, F. J., Gong, X., White, T. W., and Mathias, R. T. (2004). Connections between Connexins, Calcium, and Cataracts in the Lens. J. Gen. Physiol. 124 (4), 289-300. doi:10.1085/jgp.200409121

Gao, J., Wang, H., Sun, X., Varadaraj, K., Li, L., White, T. W., et al. (2013). The Effects of Age on Lens Transport. Invest. Ophthalmol. Vis. Sci. 54 (12), 7174-7187. doi:10.1167/iovs.13-12593

Gerido, D. A., Sellitto, C., Li, L., and White, T. W. (2003). Genetic Background Influences Cataractogenesis, but Not Lens Growth Deficiency, in Cx50Knockout Mice. Invest. Ophthalmol. Vis. Sci. 44 (6), 2669-2674. doi:10. $1167 /$ iovs.02-1311

Gong, X., Cheng, C., and Xia, C. H. (2007). Connexins in Lens Development and Cataractogenesis. J. Membr. Biol. 218 (1-3), 9-12. doi:10.1007/s00232-0079033-0

Gong, X. D., Wang, Y., Hu, X.-B., Zheng, S.-Y., Fu, J.-L., Nie, Q., et al. (2021). Aging-Dependent Loss of GAP junction Proteins $\mathrm{Cx} 46$ and $\mathrm{Cx} 50$ in the Fiber Cells of Human and Mouse Lenses Accounts for the Diminished Coupling Conductance. Aging. 13 (13), 17568-17591. doi:10.18632/aging. 203247

Gong, X., Li, E., Klier, G., Huang, Q., Wu, Y., Lei, H., et al. (1997). Disruption of a3 Connexin Gene Leads to Proteolysis and Cataractogenesis in Mice. Cell. 91 (6), 833-843. doi:10.1016/s0092-8674(00)80471-7

Graw, J., Löster, J., Soewarto, D., Fuchs, H., Meyer, B., Reis, A., et al. (2001). Characterization of a Mutation in the Lens-Specific MP70 Encoding Gene of the Mouse Leading to a Dominant Cataract. Exp. Eye Res. 73 (6), 867-876. doi:10.1006/exer.2001.1096

Hadrami, M., Bonnet, C., Veten, F., Zeitz, C., Condroyer, C., Wang, P., et al. (2019). A Novel Missense Mutation of GJA8 Causes Congenital Cataract in a Large Mauritanian Family. Eur. J. Ophthalmol. 29 (6), 621-628. doi:10.1177/ 1120672118804757

Hashemi, H., Pakzad, R., Yekta, A., Aghamirsalim, M., Pakbin, M., Ramin, S., et al. (2020). Global and Regional Prevalence of Age-Related Cataract: a Comprehensive Systematic Review and Meta-Analysis. Eye. 34 (8), 1357-1370. doi:10.1038/s41433-020-0806-3

Ho, Y.-S., Magnenat, J.-L., Bronson, R. T., Cao, J., Gargano, M., Sugawara, M., et al. (1997). Mice Deficient in Cellular Glutathione Peroxidase Develop Normally and Show No Increased Sensitivity to Hyperoxia. J. Biol. Chem. 272 (26), 16644-16651. doi:10.1074/jbc.272.26.16644

Jara, O., Minogue, P. J., Berthoud, V. M., and Beyer, E. C. (2020). Do Connexin Mutants Cause Cataracts by Perturbing Glutathione Levels and Redox Metabolism in the Lens? Biomolecules. 10 (10), 1418. doi:10.3390/ biom 10101418

Katai, N., Kikuchi, T., Shibuki, H., Kuroiwa, S., Arai, J., Kurokawa, T., et al. (1999). Caspaselike Proteases Activated in Apoptotic Photoreceptors of Royal College of Surgeons Rats. Invest. Ophthalmol. Vis. Sci. 40 (8), 1802-1807. doi:10.1007/ s004170050286

Kelly, S. M., Vanslyke, J. K., and Musil, L. S. (2007). Regulation of UbiquitinProteasome System-Mediated Degradation by Cytosolic Stress. MBoC. 18 (11), 4279-4291. doi:10.1091/mbc.e07-05-0487

King, T. J., and Lampe, P. D. (2005). Temporal Regulation of Connexin Phosphorylation in Embryonic and Adult Tissues. Biochim. Biophys. Acta. 1719 (1-2), 24-35. doi:10.1016/j.bbamem.2005.07.010

Laver, N. M., Robinson, W. G., Calvin, H. I., and Fu, S.-C. J. (1993). Early Epithelial Lesions in Cataracts of GSH-Depleted Mouse Pups. Exp. Eye Res. 57 (4), 493-498. doi:10.1006/exer.1993.1151

Li, L., Chang, B., Cheng, C., Chang, D., Hawes, N. L., Xia, C.-h., et al. (2008). Dense Nuclear Cataract Caused by the $\gamma \mathrm{B}$-Crystallin S11R Point Mutation. Invest. Ophthalmol. Vis. Sci. 49 (1), 304-309. doi:10.1167/iovs.07-0942 
Li, L., Cheng, C., Xia, C.-h., White, T. W., Fletcher, D. A., and Gong, X. (2010). Connexin Mediated Cataract Prevention in Mice. PLoS One. 5 (9), e12624. doi:10.1371/journal.pone.0012624

Li, L., Fan, D.-B., Zhao, Y.-T., Li, Y., Yang, Z.-B., and Zheng, G.-Y. (2019). GJA8 Missense Mutation Disrupts Hemichannels and Induces Cell Apoptosis in Human Lens Epithelial Cells. Sci. Rep. 9 (1), 19157. doi:10.1038/s41598-01955549-1

Li, Y., Wang, J., Dong, B., and Man, H. (2004). A Novel Connexin46 (GJA3) Mutation in Autosomal Dominant Congenital Nuclear Pulverulent Cataract. Mol. Vis. 10, 668-671. doi:10.1021/bi049306z

Lim, J. C., Grey, A. C., Zahraei, A., and Donaldson, P. J. (2020). Age-Dependent Changes in Glutathione Metabolism Pathways in the Lens: New Insights into Therapeutic Strategies to Prevent Cataract Formation-A Review. Clin. Exp. Ophthalmol. 48 (8), 1031-1042. doi:10.1111/ceo.13801

Lin, D., and Takemoto, D. J. (2005). Oxidative Activation of Protein Kinase $\mathrm{C} \gamma$ through the C1 Domain. J. Biol. Chem. 280 (14), 13682-13693. doi:10.1074/jbc. $\mathrm{m} 407762200$

Liu, K., Lyu, L., Chin, D., Gao, J., Sun, X., Shang, F., et al. (2015). Altered Ubiquitin Causes Perturbed Calcium Homeostasis, Hyperactivation of Calpain, Dysregulated Differentiation, and Cataract. Proc. Natl. Acad. Sci. USA. 112 (4), 1071-1076. doi:10.1073/pnas.1404059112

Liu, Y., Ke, M., Yan, M., Guo, S., Mothobi, M. E., Chen, Q., et al. (2011). Association between gap junction Protein-Alpha 8 Polymorphisms and Age-Related Cataract. Mol. Biol. Rep. 38 (2), 1301-1307. doi:10.1007/ s11033-010-0230-z

Mackay, D., Ionides, A., Kibar, Z., Rouleau, G., Berry, V., Moore, A., et al. (1999). Connexin 46 Mutations in Autosomal Dominant Congenital Cataract. Am. J. Hum. Genet. 64 (5), 1357-1364. doi:10.1086/302383

Mathias, R. T., Kistler, J., and Donaldson, P. (2007). The Lens Circulation. J. Membr. Biol. 216 (1), 1-16. doi:10.1007/s00232-007-9019-y

Mese, G., Richard, G., and White, T. W. (2007). Gap Junctions: Basic Structure and Function. J. Invest. Dermatol. 127 (11), 2516-2524. doi:10.1038/sj.jid.5700770

Minogue, P. J., Gao, J., Zoltoski, R. K., Novak, L. A., Mathias, R. T., Beyer, E. C., et al. (2017). Physiological and Optical Alterations Precede the Appearance of Cataracts in Cx46fs380 Mice. Invest. Ophthalmol. Vis. Sci. 58 (10), 4366-4374. doi:10.1167/iovs.17-21684

Minogue, P. J., Liu, X., Ebihara, L., Beyer, E. C., and Berthoud, V. M. (2005). An Aberrant Sequence in a Connexin 46 Mutant Underlies Congenital Cataracts. J. Biol. Chem. 280 (49), 40788-40795. doi:10.1074/jbc.m504765200

Molina, S. A., and Takemoto, D. J. (2012). The Role of Connexin 46 Promoter in Lens and Other Hypoxic Tissues. Communicative Integr. Biol. 5 (2), 114-117. doi:10.4161/cib.18715

Okafor, M., Tamiya, S., and Delamere, N. A. (2003). Sodium-calcium Exchange Influences the Response to Endothelin-1 in Lens Epithelium. Cell Calcium. 34 (3), 231-240. doi:10.1016/s0143-4160(03)00085-x

Paul, D. L., Ebihara, L., Takemoto, L. J., Swenson, K. I., and Goodenough, D. A. (1991). Connexin46, a Novel Lens gap junction Protein, Induces Voltage-Gated Currents in Nonjunctional Plasma Membrane of Xenopus Oocytes. J. Cell Biol. 115 (4), 1077-1089. doi:10.1083/jcb.115.4.1077

Ping, X., Liang, J., Shi, K., Bao, J., Wu, J., Yu, X., et al. (2021). Rapamycin Relieves the Cataract Caused by Ablation of Gja8b Through Stimulating Autophagy in Zebrafish. Autophagy. 17 (11), 3323-3337. doi:10.1080/ 15548627.2021.1872188

Ponnam, S. P. G., Ramesha, K., Tejwani, S., Ramamurthy, B., and Kannabiran, C. (2007). Mutation of the gap Junction Protein Alpha 8 (GJA8) Gene Causes Autosomal Recessive Cataract. J. Med. Genet. 44 (7), e85. doi:10.1136/jmg.2007. 050138

Rees, M. I., Watts, P., Fenton, I., Clarke, A., Snell, R. G., Owen, M. J., et al. (2000). Further Evidence of Autosomal Dominant Congenital Zonular Pulverulent Cataracts Linked to 13q11 (CZP3) and a Novel Mutation in Connexin 46 (GJA3). Hum. Genet. 106 (2), 206-209. doi:10.1007/ s004399900234

Retamal, M. A., Fiori, M. C., Fernandez-Olivares, A., Linsambarth, S., Peña, F., Quintana, D., et al. (2020). 4-Hydroxynonenal Induces Cx46 Hemichannel Inhibition Through its Carbonylation. Biochim. Biophys. Acta (Bba) - Mol. Cell Biol. Lipids. 1865 (8), 158705. doi:10.1016/j.bbalip.2020.158705

Retamal, M. A., Orellana, V. P., Arévalo, N. J., Rojas, C. G., Arjona, R. J., Alcaíno, C. A., et al. (2019). Cx46 Hemichannel Modulation by Nitric Oxide: Role of the
Fourth Transmembrane helix Cysteine and its Possible Involvement in Cataract Formation. Nitric Oxide. 86, 54-62. doi:10.1016/j.niox.2019.02.007

Rozema, J. J., and Ní Dhubhghaill, S. (2020). Age-related Axial Length Changes in Adults: a Review. Ophthalmic Physiol. Opt. 40 (6), 710-717. doi:10.1111/opo. 12728

Ruan, X., Liu, Z., Luo, L., and Liu, Y. (2020). The Structure of the Lens and its Associations with the Visual Quality. BMJ Open Ophth. 5 (1), e000459. doi:10. 1136/bmjophth-2020-000459

Sánchez, A., Castro, C., Flores, D.-L., Gutiérrez, E., and Baldi, P. (2019). Gap Junction Channels of Innexins and Connexins: Relations and Computational Perspectives. Int. J. Mol. Sci. 20 (10), 2476. doi:10.3390/ijms20102476

Schadzek, P., Stahl, Y., Preller, M., and Ngezahayo, A. (2019). Analysis of the Dominant Mutation N188T of Human Connexin46 ( hC X46) Using Concatenation and Molecular Dynamics Simulation. FEBS Open Bio. 9 (5), 840-850. doi:10.1002/2211-5463.12624

Sellitto, C., Li, L., and White, T. W. (2004). Connexin50 Is Essential for normal Postnatal Lens Cell Proliferation. Invest. Ophthalmol. Vis. Sci. 45 (9), 3196-3202. doi:10.1167/iovs.04-0194

Serebryany, E., Thorn, D. C., and Quintanar, L. (2021). Redox Chemistry of Lens Crystallins: A System of Cysteines. Exp. Eye Res. 211, 108707. doi:10.1016/j. exer.2021.108707

Sharan, S., Grigg, J. R., and Billson, F. A. (2005). Bilateral Naevus of Ota with Choroidal Melanoma and Diffuse Retinal Pigmentation in a Dark Skinned Person. Br. J. Ophthalmol. 89 (11), 1529. doi:10.1136/bjo.2005.070839

Shi, W., Riquelme, M. A., Gu, S., and Jiang, J. X. (2018). Connexin Hemichannels Mediate Glutathione Transport and Protect Lens Fiber Cells from Oxidative Stress. J. Cell Sci. 131 (6), jcs212506. doi:10.1242/jcs.212506

Shiels, A., and Hejtmancik, J. F. (2021). Inherited Cataracts: Genetic Mechanisms and Pathways New and Old. Exp. Eye Res. 209, 108662. doi:10.1016/j.exer.2021. 108662

Slavi, N., Wang, Z., Harvey, L., Schey, K. L., and Srinivas, M. (2016). Identification and Functional Assessment of Age-dependent Truncations to Cx46 and Cx50 in the Human Lens. Invest. Ophthalmol. Vis. Sci. 57 (13), 5714-5722. doi:10. 1167/iovs.16-19698

Steele, E. C., Lyon, M. F., Favor, J., Guillot, P. V., Boyd, Y., and Church, R. L. (1998). A Mutation in the Connexin 50 (Cx50) Gene Is a Candidate for the No2 Mouse Cataract. Curr. Eye Res. 17 (9), 883-889. doi:10.1076/ceyr.17.9.883.5144

Summers, J. A., Schaeffel, F., Marcos, S., Wu, H., and Tkatchenko, A. V. (2021). Functional Integration of Eye Tissues and Refractive Eye Development: Mechanisms and Pathways. Exp. Eye Res. 209, 108693. doi:10.1016/j.exer. 2021.108693

Taylan Sekeroglu, H., and Utine, G. E. (2021). Congenital Cataract and its Genetics: The Era of Next-Generation Sequencing. Turk J. Ophthalmol. 51 (2), 107-113. doi:10.4274/tjo.galenos.2020.08377

Tong, J. J., Khan, U., Haddad, B. G., Minogue, P. J., Beyer, E. C., Berthoud, V. M., et al. (2021). Molecular Mechanisms Underlying Enhanced Hemichannel Function of a Cataract-Associated Cx50 Mutant. Biophys. J. 3495 (21), 00951-00956. doi:10.1016/j.bpj.2021.11.004

Valiunas, V., Brink, P. R., and White, T. W. (2019). Lens Connexin Channels Have Differential Permeability to the Second Messenger cAMP. Invest. Ophthalmol. Vis. Sci. 60 (12), 3821-3829. doi:10.1167/iovs.19-27302

Valiunas, V., and White, T. W. (2020). Connexin43 and Connexin50 Channels Exhibit Different Permeability to the Second Messenger Inositol Triphosphate. Sci. Rep. 10 (1), 8744. doi:10.1038/s41598-020-65761-z

Van Campenhout, R., Gomes, A. R., De Groof, T. W. M., Muyldermans, S., Devoogdt, N., and Vinken, M. (2021). Mechanisms Underlying Connexin Hemichannel Activation in Disease. Int. J. Mol. Sci. 22 (7), 3503. doi:10. 3390/ijms22073503

Vanden Abeele, F., Bidaux, G., Gordienko, D., Beck, B., Panchin, Y. V., Baranova, A. V., et al. (2006). Functional Implications of Calcium Permeability of the Channel Formed by Pannexin 1. J. Cell Biol. 174 (4), 535-546. doi:10.1083/jcb. 200601115

Wang, H., Gao, J., Sun, X., Martinez-Wittinghan, F. J., Li, L., Varadaraj, K., et al. (2009). The Effects of GPX-1 Knockout on Membrane Transport and Intracellular Homeostasis in the Lens. J. Membr. Biol. 227 (1), 25-37. doi:10.1007/s00232-008-9141-5

White, T. W., Gao, Y., Li, L., Sellitto, C., and Srinivas, M. (2007). Optimal Lens Epithelial Cell Proliferation Is Dependent on the Connexin Isoform Providing 
gap Junctional Coupling. Invest. Ophthalmol. Vis. Sci. 48 (12), 5630-5637. doi:10.1167/iovs.06-1540

White, T. W., Goodenough, D. A., and Paul, D. L. (1998). Targeted Ablation of Connexin50 in Mice Results in Microphthalmia and Zonular Pulverulent Cataracts. J. Cell Biol. 143 (3), 815-825. doi:10.1083/jcb.143.3.815

Xia, C. H., Cheng, C., Huang, Q., Cheung, D., Li, L., Dunia, I., et al. (2006a). Absence of $a 3$ (Cx46) and $a 8$ (Cx50) Connexins Leads to Cataracts by Affecting Lens Inner Fiber Cells. Exp. Eye Res. 83 (3), 688-696. doi:10.1016/j.exer.2006. 03.013

Xia, C. H., Cheung, D., DeRosa, A. M., Chang, B., Lo, W. K., White, T. W., et al. (2006b). Knock-in of Alpha3 Connexin Prevents Severe Cataracts Caused by an Alpha8 point Mutation. J. Cell Sci. 119 (Pt 10), 2138-2144. doi:10.1242/jcs. 02940

Yamashita, S., Furumoto, K., Nobukiyo, A., Kamohara, M., Ushijima, T., and Furukawa, T. (2002). Mapping of A Gene Responsible for Cataract Formation and its Modifier in the UPL Rat. Invest. Ophthalmol. Vis. Sci. 43 (10), 3153-3159. doi:10.1007/s00417-002-0538-z

Yoshida, M., Harada, Y., Kaidzu, S., Ohira, A., Masuda, J., and Nabika, T. (2005). New Genetic Model Rat for Congenital Cataracts Due to a Connexin 46 (Gja3 ) Mutation. Pathol. Int. 55 (11), 732-737. doi:10. 1111/j.1440-1827.2005.01896.x

Yue, B., Haddad, B. G., Khan, U., Chen, H., Atalla, M., Zhang, Z., et al. (2021). Connexin 46 and Connexin 50 gap junction Channel Properties Are Shaped by Structural and Dynamic Features of Their N-Terminal Domains. J. Physiol. 599 (13), 3313-3335. doi:10.1113/JP281339
Zhao, L., Wang, J., Zhang, Y., Wang, L., Yu, M., and Wang, F. (2020). Vitamin C Decreases VEGF Expression Levels via Hypoxia inducible Factor 1 $\alpha$ Dependent and Independent Pathways in Lens Epithelial Cells. Mol. Med. Rep. 22 (1), 436-444. doi:10.3892/mmr.2020.11103

Zhou, Z., Wang, B., Hu, S., Zhang, C., Ma, X., and Qi, Y. (2011). Genetic Variations in GJA3, GJA8, LIM2, and Age-Related Cataract in the Chinese Population: a Mutation Screening Study. Mol. Vis. 17, 621-626. doi:10.1017/ S0952523810000489

Conflict of Interest: The authors declare that the research was conducted in the absence of any commercial or financial relationships that could be construed as a potential conflict of interest.

Publisher's Note: All claims expressed in this article are solely those of the authors and do not necessarily represent those of their affiliated organizations, or those of the publisher, the editors and the reviewers. Any product that may be evaluated in this article, or claim that may be made by its manufacturer, is not guaranteed or endorsed by the publisher.

Copyright $\odot 2022$ Shi, Li and Yang. This is an open-access article distributed under the terms of the Creative Commons Attribution License (CC BY). The use, distribution or reproduction in other forums is permitted, provided the original author(s) and the copyright owner(s) are credited and that the original publication in this journal is cited, in accordance with accepted academic practice. No use, distribution or reproduction is permitted which does not comply with these terms. 